\title{
Unexpected Pleiotropic Effects of SGLT2 Inhibitors: Pearls and Pitfalls of This Novel Antidiabetic Class
}

\author{
Hideaki Kaneto ${ }^{1, *(1)}$, Atsushi Obata ${ }^{1}$ D, Tomohiko Kimura ${ }^{1}$, Masashi Shimoda ${ }^{1}$, Tomoe Kinoshita ${ }^{1}$, \\ Taka-aki Matsuoka ${ }^{2}$ and Kohei Kaku ${ }^{3}$
}

1 Department of Diabetes, Endocrinology and Metabolism, Kawasaki Medical School, 577 Matsushima, Kurashiki 701-0192, Japan; obata-tky@med.kawasaki-m.ac.jp (A.O.); tomohiko@med.kawasaki-m.ac.jp (T.K.); masashi-s@med.kawasaki-m.ac.jp (M.S.); kinoshita@med.kawasaki-m.ac.jp (T.K.)

2 The First Department of Internal Medicine, Wakayama Medical University, Wakayama 641-8510, Japan; matsuoka@wakayama-med.ac.jp

3 Department of General Internal Medicine 1, Kawasaki Medical School, 577 Matsushima, Kurashiki 701-0192, Japan; kka@med.kawasaki-m.ac.jp

* Correspondence: kaneto@med.kawasaki-m.ac.jp

check for updates

Citation: Kaneto, H.; Obata, A.; Kimura, T.; Shimoda, M.; Kinoshita,

T.; Matsuoka, T.-a.; Kaku, K.

Unexpected Pleiotropic Effects of SGLT2 Inhibitors: Pearls and Pitfalls of This Novel Antidiabetic Class. Int. J. Mol. Sci. 2021, 22, 3062. https:// doi.org/10.3390/ijms22063062

Academic Editor:

Dumitru Constantin-Teodosiu

Received: 17 February 2021

Accepted: 14 March 2021

Published: 17 March 2021

Publisher's Note: MDPI stays neutral with regard to jurisdictional claims in published maps and institutional affiliations.

Copyright: (c) 2021 by the authors. Licensee MDPI, Basel, Switzerland. This article is an open access article distributed under the terms and conditions of the Creative Commons Attribution (CC BY) license (https:// creativecommons.org/licenses/by/ $4.0 /)$.

\begin{abstract}
Sodium-glucose co-transporter 2 (SGLT2) inhibitors facilitate urine glucose excretion by reducing glucose reabsorption, leading to ameliorate glycemic control. While the main characteristics of type 2 diabetes mellitus are insufficient insulin secretion and insulin resistance, SGLT2 inhibitors have some favorable effects on pancreatic $\beta$-cell function and insulin sensitivity. SGLT2 inhibitors ameliorate fatty liver and reduce visceral fat mass. Furthermore, it has been noted that SGLT2 inhibitors have cardio-protective and renal protective effects in addition to their glucose-lowering effect. In addition, several kinds of SGLT2 inhibitors are used in patients with type 1 diabetes mellitus as an adjuvant therapy to insulin. Taken together, SGLT2 inhibitors have amazing multifaceted effects that are far beyond prediction like some emerging magical medicine. Thereby, SGLT2 inhibitors are very promising as relatively new anti-diabetic drugs and are being paid attention in various aspects. It is noted, however, that SGLT2 inhibitors have several side effects such as urinary tract infection or genital infection. In addition, we should bear in mind the possibility of diabetic ketoacidosis, especially when we use SGLT2 inhibitors in patients with poor insulin secretory capacity.
\end{abstract}

Keywords: pancreatic $\beta$-cells; insulin resistance; fatty liver; cardio-protection; renal protection

\section{Introduction}

The number of patients with type 2 diabetes mellitus (T2DM) has markedly increased all over the world due to various changes in lifestyle. The main characteristics of T2DM are insufficient $\beta$-cell function and insulin resistance [1-3]. Since sodium-glucose cotransporter 2 (SGLT2) contributes to most of renal glucose reabsorption, inhibition of SGLT2 is promising for T2DM [4-11]. In this review article, we show that SGLT2 inhibitors have surprisingly many multifaceted effects beyond prediction like some emerging magical medicine. SGLT2 inhibitors protect pancreatic $\beta$-cells from glucose toxicity and mitigate insulin resistance, which finally ameliorates glycemic control. Moreover, while nonalcoholic fatty liver disease (NAFLD) is often brought out in patients with T2DM, it has been shown that SGLT2 inhibitors ameliorate NAFLD. Furthermore, attention has been paid to the fact that SGLT2 inhibitors have cardio-protective and renal protective effects beyond their glucose-lowering effect.

\section{Concept of Pancreatic $\beta$-Cell Glucose Toxicity Found in Type 2 Diabetes Mellitus}

The main characteristics of T2DM are insufficient insulin secretion and insulin resistance. Under healthy conditions, blood glucose levels are well controlled by insulin. Under diabetic conditions, however, increased insulin resistance impairs insulin biosynthesis and 
secretion. First, insulin resistance is brought out by overeating and/or lack of exercise, but enough amount of insulin is secreted so that insulin resistance is compensated. However, when $\beta$-cells are exposed to high glucose concentration for a long period of time, $\beta$-cell function gradually declines due to overwork. Insulin biosynthesis and secretion decline together with reduction of insulin gene transcription factors MafA and PDX-1 [12-16] (Figure 1). Finally, $\beta$-cell number is decreased apoptosis and/or de-differentiation. Such phenomena are called $\beta$-cell glucose toxicity. It has been shown, however, that $\beta$-cell function is recovered by an appropriate intervention with various anti-diabetes agents [17-22]. Chronic hyperglycemia also impairs insulin signaling in insulin target tissues, which leads to the progression of insulin resistance. Therefore, glucose toxicity is involved in insulin resistance in addition to $\beta$-cell dysfunction.

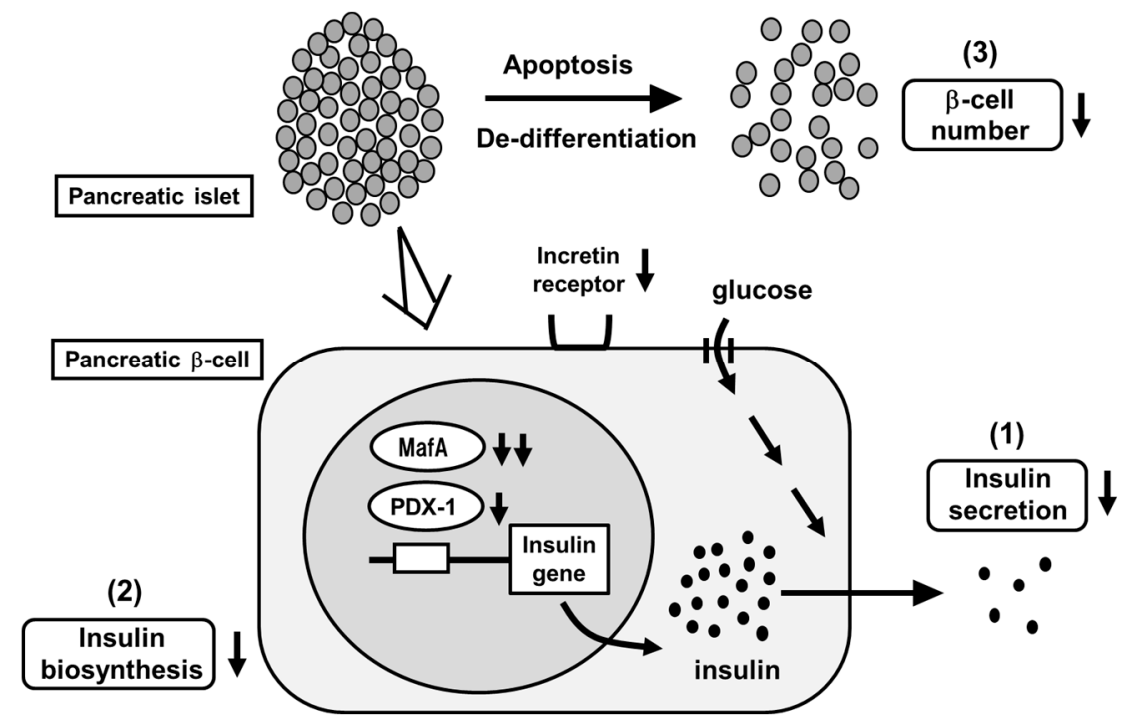

Figure 1. Pancreatic $\beta$-cell glucose toxicity found in type 2 diabetes mellitus (T2DM). When pancreatic $\beta$-cells are exposed to chronic hyperglycemia, $\beta$-cell function gradually declines. First, insulin secretion is reduced. Second, insulin biosynthesis is reduced together with reduction of MafA and PDX-1 expression. Third, $\beta$-cell number is decreased through the process of apoptosis and/or de-differentiation.

MafA is a potent insulin gene transcription factor [12-15]. MafA expression level is markedly decreased under diabetic conditions but it is preserved after reduction of glucose toxicity with insulin or other anti-diabetic agents. Furthermore, we reported that serum insulin levels were increased and blood glucose levels were decreased by preservation of MafA expression in $\beta$-cells in obese type 2 diabetic $\mathrm{db} / \mathrm{db}$ mice using the Cre-loxP system. In addition, $\beta$-cell mass was preserved by MafA overexpression [15]. We think that these findings show that reduction of MafA expression leads to $\beta$-cell dysfunction found in T2DM. PDX-1 is also an insulin gene transcription factor and plays an important role in $\beta$-cells, but its expression level declines after exposure to chronic hyperglycemia $[12,13]$. We think that such reduction of PDX-1 also leads to $\beta$-cell dysfunction found in T2DM. Indeed, glucose-stimulated insulin secretion was enhanced, and glycemic control was ameliorated by preservation of PDX-1 expression in $\beta$-cells using the Cre-loxP system [16]. Taken together, we believe that that reduction of MafA and PDX-1 expression leads to $\beta$-cell dysfunction found in T2DM.

Furthermore, while there are several reports indicating the role of insulin signaling in endothelial cells [23-26], it seems that endothelial dysfunction is also associated with $\beta$-cell dysfunction. We assume that since pancreatic islets are easily damaged by ischemia or various stress, $\beta$-cell dysfunction is brought out by endothelial dysfunction. Actually, we recently reported that in vascular endothelial cell-specific knockout mice of PDK1, one of the important molecules in insulin signaling, $\beta$-cell dysfunction, was brought out together 
with reduction of vascularity in islets, fall into ischemic state, and increase of inflammation and endoplasmic reticulum stress in $\beta$-cells [26]. Since such phenotypes are very similar to the phenomena found under diabetic conditions, we assume that endothelial dysfunction is also, at least in part, associated with $\beta$-cell dysfunction found in T2DM.

\section{SGLT2 Inhibitors Ameliorate Hyperglycemia by Increasing Urinary Glucose Excretion}

SGLT2 inhibitors are often used in patients with T2DM worldwide [4-11]. SGLT2 inhibitors lead to amelioration of glycemic control by enhancing urinary glucose excretion. In addition, it is known that, under diabetic conditions, SGLT2 expression in the kidney is augmented, leading to increase renal glucose reabsorption. There is a large amount of evidence worldwide regarding the efficacy and safety of SGLT2 inhibitors in patients with T2DM. Tofogliflozin has high selectivity for SGLT2 and canagliflozin has low selectivity [27], but it is still controversial whether such difference is important or not for our bodies. In addition, dual SGLT1/2 inhibitors were also developed, and their effects are also promising. It was reported that dual SGLT1/2 inhibitors increased GLP-1 levels and reduced postprandial glucose levels [28].

\section{SGLT2 Inhibitors Have Some Favorable Effects on Pancreatic $\beta$-Cells}

It has been shown that SGLT2 inhibitors protect pancreatic $\beta$-cells from glucose toxicity [29-36]. Indeed, it was reported that an SGLT2 inhibitor luseogliflozin preserved $\beta$-cell function in obese type 2 diabetic $\mathrm{db} / \mathrm{db}$ mice [35]. Pancreatic $\beta$-cell mass was significantly increased by luseogliflozin treatment. In addition, $\beta$-cell proliferation was increased, and $\beta$-cell apoptosis was decreased by such treatment. Insulin biosynthesis and expression levels of MafA and PDX-1 were also enhanced by such treatment [35]. Taken together, SGLT2 inhibitors have some favorable effects for the preservation of $\beta$-cell function (Figure 2).

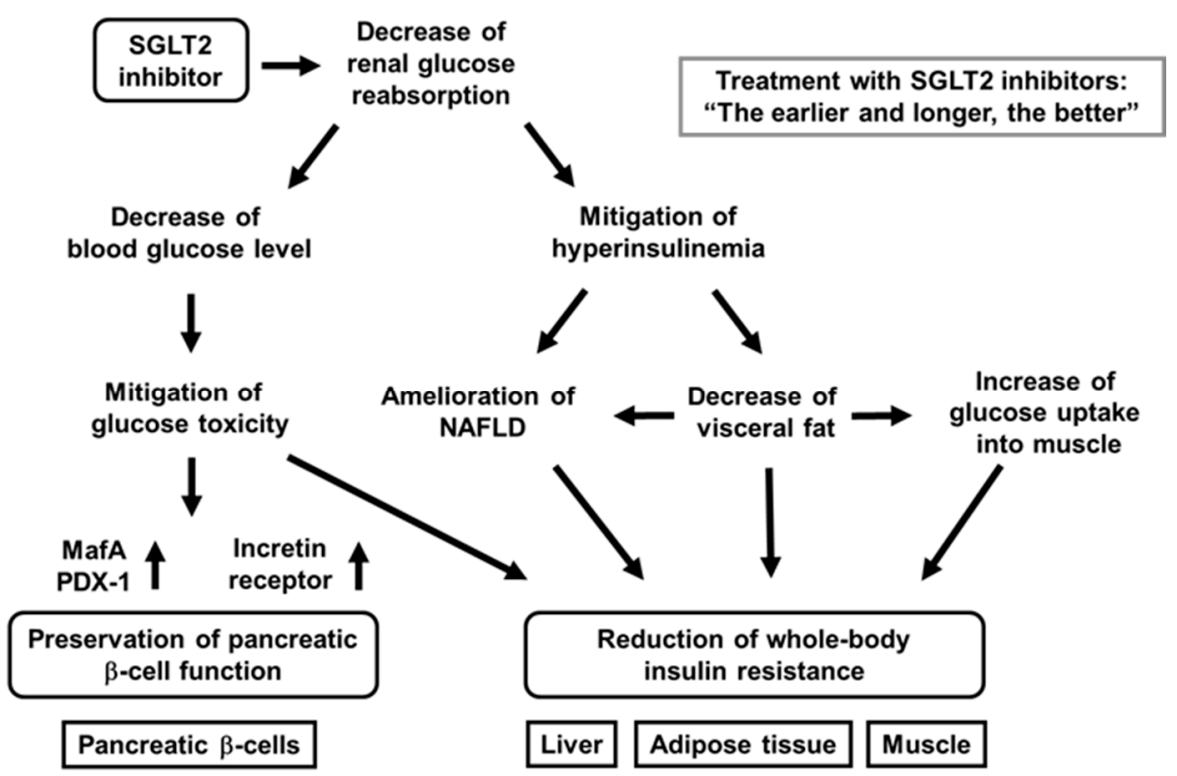

Figure 2. Favorable effects of sodium-glucose cotransporter 2 (SGLT2) inhibitors on pancreatic $\beta$-cells and various insulin target tissues. SGLT2 inhibitors ameliorates glycemic control and alleviates hyperinsulinemia by reducing renal glucose reabsorption. Amelioration of glycemic control reduces glucose toxicity, which finally preserves $\beta$-cell function and mitigation of insulin resistance in insulin target tissues. Alleviation of hyperinsulinemia ameliorates fatty liver or nonalcoholic fatty liver disease (NAFLD), reduces visceral fat, and increases glucose uptake into skeletal muscle, all of which finally lead to mitigation of whole-body insulin resistance. 
In addition, to focus on the direct effects of SGLT2 inhibitor on $\beta$-cells, researchers performed similar experiments for only 1 week with empagliflozin [34]. As a result, lipid metabolism was not influenced, but empagliflozin showed protective effects on $\beta$-cells. Insulin, MafA, and PDX-1 expression was increased by empagliflozin treatment. These data indicate that SGLT2 inhibitor directly protect $\beta$-cells from glucose toxicity [34] (Figure 2).

Furthermore, we recently compared the protective effects of luseogliflozin on $\beta$-cell function and mass between at an early and at advanced stage of diabetes and between after short-term usage and long-term usage using diabetic $\mathrm{db} / \mathrm{db}$ mice [36]. In terms of the results, $\beta$-cell function was preserved by luseogliflozin treatment at an early stage of diabetes, but not at advanced stage. Moreover, $\beta$-cell mass was increased by such treatment only at an early stage. Furthermore, when $\mathrm{db} / \mathrm{db}$ mice were treated with luseogliflozin for a long period of time from an early stage, insulin biosynthesis and secretion were preserved, even at an advanced stage [36]. Taken together, SGLT2 inhibitors have more favorable effects at an early stage, and long-term usage of SGLT2 inhibitors have more favorable effects on $\beta$-cells rather than short-term usage (Figure 2).

While various studies were actively performed regarding the role of $\alpha$-cells [37], it was shown that SGLT2 was present in $\alpha$-cells and that dapagliflozin enhanced glucagon secretion, leading to the increase of hepatic gluconeogenesis [38]. In spite of such augmentation, blood glucose levels were decreased by dapagliflozin, probably due to the increase of glycosuria. It was also shown that dapagliflozin facilitated glucagon secretion and gluconeogenesis in healthy mice, which limited the reduction of blood glucose levels induced by fasting [38]. It is noted, however, that the direct effect of SGLT2 inhibition on glucagon secretion is currently a controversial topic. For example, one group showed SGLT2 expression in human islets and thought dapagliflozin directly stimulated glucagon secretion through SGLT2 inhibition in $\alpha$-cells [38], whereas another group showed that SGLT2 expression was not detectable in human or mouse islets [39]. Furthermore, very recently, the importance of SGLT2 activity on glucagon secretion was evaluated by using isolated perfused rat pancreas. As the results, glucagon secretion was decreased by high glucose, but it was not affected by SGLT2 inhibitors. They concluded that increased glucagon secretion by SGLT2 inhibitor was not due to direct effect of SGLT2 on $\alpha$-cells [40].

\section{SGLT2 Inhibitors Have Some Favorable Effects on Insulin Resistance}

It is known that SGLT2 inhibitors show favorable effects on insulin target tissues. Usage of SGLT2 inhibitors lead to amelioration of fatty liver, reduction of visceral fat mass, and mitigation of insulin resistance [41-47] (Figure 2). Indeed, tofogliflozin decreased insulin resistance and ameliorated glycemic control in diabetic mice [46]. In this study, C57BL/ 6 mice were given normal chow or high-fat chow containing tofogliflozin. As a result, tofogliflozin decreased body weight and blood glucose levels in diabetic mice. In addition, adipocyte size and fat mass were reduced by tofogliflozin, which finally enhanced insulin sensitivity [46]. Excess insulin secretion was decreased by tofogliflozin, which led to increase of lipolysis, $\beta$-oxidation, and ketone bodies. Such reduction of excess insulin secretion increased gluconeogenesis and decreased lipogenesis. The decrease of lipogenesis led to the decrease of triglyceride content in the liver. Furthermore, hyper-insulinemic euglycemic clamp study showed that insulin resistance was reduced by tofogliflozin mainly due to increase of glucose uptake into skeletal muscle [46]. Taken together, tofogliflozin mitigates insulin resistance mainly through the increase of lipolysis in adipose tissues and glucose uptake into skeletal muscle (Figure 2). In addition, it was shown that ipragliflozin decreased fat mass mainly through the increase of fatty acid oxidation in high-fat dietinduced obese rats and that tofogliflozin reduced fat accumulation in diet-induced obese rats and KKAy mice [41,42].

It has been reported that SGLT2 inhibitors show some favorable effects in patients with T2DM as well [43-45]. It was shown that dapagliflozin reduced blood glucose levels and fat mass for a long time in patients with T2DM. In addition, it was shown that dapagliflozin enhanced insulin sensitivity in skeletal muscle but increased hepatic glucose production 
(HGP) in patients with T2DM. In this study, patients with T2DM were randomized to take dapagliflozin or placebo, and HGP was evaluated using the clamp technique. As a result, HGP as well as plasma glucagon level were increased by dapagliflozin. They showed that the improvement of glycemic control with dapagliflozin enhanced insulin sensitivity in skeletal muscle but increased HGP. It was also reported that HGP and glucagon level were enhanced by empagliflozin in patients with T2DM. We assume that the increase of HGP does not necessarily indicate the aggravation of insulin resistance in the liver. It is possible that such enhancement of HGP with SGLT2 treatment is, at least in part, related to the decreased ratio of serum insulin/glucagon.

\section{SGLT2 Inhibitors Have Some Favorable Effects on Nonalcoholic Fatty Liver Disease (NAFLD) Though the Alleviation of Hyperinsulinemia}

NAFLD is often observed in clinical practice, and the number of patients with NAFLD has been markedly increased all over the world. NAFLD includes a simple fatty liver and nonalcoholic steatohepatitis (NASH), together with fibrosis and inflammation [48-51]. Patients with T2DM have higher risk of NAFLD, and the presence of T2DM tends to aggravate NAFLD [52-54]. It was also reported that patients with T2DM had higher risk for liver cirrhosis and hepatocellular carcinoma [55]. Previously, hepatitis $C$ virus and heavy usage of alcohol were the main two causes of liver cirrhosis and hepatocellular carcinoma. However, recently, hepatitis $\mathrm{C}$ has become curable and it has been noted that various liver disorders are brought out in subjects without drinking alcohol. Diabetes mellitus has become one of the risk factors of liver disorders instead of hepatitis $C$ virus and heavy usage of alcohol, and recently malignancies including hepatocellular carcinoma have sometimes been regarded as diabetic complications in addition to classical diabetic micro- and macro-complications. It is well known that thiazolidinediones have favorable effects on NAFLD [56,57]. However, thiazolidinediones often increase body weight, and thereby usage of thiazolidinediones is not necessarily appropriate in patients with T2DM and NAFLD.

It has been noted that SGLT2 inhibitors have some favorable effects on the liver [58-61]. It was reported that ipragliflozin and pioglitazone were effective on NAFLD in patients with T2DM and NAFLD [58]. The patients were randomized to take ipragliflozin or pioglitazone. As a result, the liver-to-spleen ratio on computed tomography (CT) was increased in either ipragliflozin or pioglitazone group. Diabetes markers such as $\mathrm{HbA} 1 \mathrm{c}$ and plasma glucose levels were similarly reduced in the two groups. However, body weight and visceral fat area were significantly reduced only in the ipragliflozin group. Moreover, they showed that both drugs had favorable effects on NAFLD and glycemic control to a similar extent in patients with T2DM and NAFLD [58]. We also reported the effects of three oral anti-diabetic drugs (dapagliflozin, pioglitazone, and glimepiride) on NAFLD in a prospective clinical trial in patients with T2DM and NAFLD [60]. We evaluated the alteration of the liver-to-spleen ratio on CT. As a result, glycemic control was improved in the three groups to almost the same extent. Significant reduction of body weight and visceral fat area was observed in the dapagliflozin group, and marked increase of serum adiponectin level was observed in the pioglitazone group. The liver-to-spleen ratio was significantly increased by dapagliflozin or pioglitazone, but not by glimepiride. However, these two drugs seemed to have different mechanism of action. Dapagliflozin showed favorable effects on NAFLD by alleviating hyperinsulinemia, while pioglitazone exerted such effects by increasing adiponectin levels [60]. Taken together, SGLT2 inhibitors are likely to have some favorable effects on NAFLD by mitigating hyperinsulinemia.

\section{SGLT2 Inhibitors Have Substantial Cardio-Protective Effects}

Various kinds of SGLT2 inhibitors have been used worldwide. There are various clinical trials about cardio-protective effects of SGLT2 inhibitors [62-68]. For example, the effects of empagliflozin on cardiovascular morbidity and mortality were shown in patients with T2DM and high cardiovascular risk. Patients were randomized to take empagliflozin or placebo. The primary composite cardiovascular events were observed in 
$10.5 \%$ patients taking empagliflozin and in $12.1 \%$ patients taking placebo. Hazard ratio (HR) in empagliflozin group was 0.86 . Furthermore, there were significant differences in rates of death from cardiovascular causes between empagliflozin and placebo group ( $3.7 \%$ vs. $5.9 \%)$, hospitalization for heart failure ( $2.7 \%$ vs. $4.1 \%)$, and death from any cause ( $5.7 \%$ vs. $8.3 \%$ ). Taken together, patients with T2DM taking empagliflozin showed the lower rate of primary composite cardiovascular outcome and lower rate of all-cause death compared to those taking placebo. In contrast, myocardial infarction and stroke were not well decreased.

The CANVAS program is another large-scale clinical trial examining the effects of SGLT2 inhibitors on cardiovascular events. The CANVAS program collected the data from two trials involving patients with T2DM and high cardiovascular risk. Patients in both trials were randomized to take canagliflozin or placebo. The rate of primary composite cardiovascular events was lower in patients taking canagliflozin compared to placebo (HR, 0.86). Taken together, it is likely that canagliflozin reduces the risk of cardiovascular events in patients with T2DM and an elevated risk of cardiovascular disease.

While SGLT2 inhibitors decreased the combined risk of cardiovascular death and hospitalization for heart failure in patients with or without T2DM in dapagliflozin and prevention of adverse-outcomes in heart failure DAPA-HF trial and EMPEROR-Reduced trial, meta-analyses of the two trials were performed recently in which the primary endpoint was time to all-cause death. As a result, the estimated treatment effect was a $13 \%$ reduction in all-cause death (HR, 0.87) and $14 \%$ reduction in cardiovascular death (HR, 0.86). The usage of SGLT2 inhibitors reduced the combined risk of cardiovascular death by $26 \%$ (HR, 0.74).

It is known that heart failure dominantly influences the prognosis in patients with T2DM. Heart failure with low ejection fraction (EF) can be treated with diuretics and/or anti-hypertensive drugs, but there are no promising drugs for heart failure with preserved ejection fraction, which is characterized by left ventricular diastolic dysfunction. It has been shown recently that SGLT2 inhibitors have some favorable effects on heart failure with preserved EF. The reduction in inflammatory cytokine signaling by SGLT2 inhibitors may explain such molecular mechanism. It is known that SGLT2 inhibitors decrease various cardiovascular risks by improving glucose and lipid metabolism. Moreover, it is well known that hypoglycemia increases cardiovascular events, and we should avoid hypoglycemia especially in patients with cardiovascular event history. The risk of hypoglycemia with SGLT2 inhibitors is quite low, especially in patients with its monotherapy.

It has been thought that increase of ketone bodies are not favorable for our body. For example, it is well known that increased ketone bodies due to lack of insulin brings out ketoacidosis. However, it has been shown recently that some amounts of ketone bodies have favorable effects on the heart. SGLT2 inhibitors usually reduce a ratio of insulin to glucagon. When this ratio is decreased, acetyl-CoA is converted to acetoacetate and $\beta$-hydroxybutyrate in the liver. Such $\beta$-hydroxybutyrate is carried to the heart in the bloodstream and taken up into the heart. $\beta$-Hydroxybutyrate is converted to acetoacetate in the heart, which leads to increased acetyl-CoA. Increased acetyl-CoA activates the TCA cycle and electron transporter chain in mitochondria and eventually increases ATP production in the heart [64] (Figure 3). Furthermore, increase of hematocrit by SGLT2 inhibitors is likely to facilitate ATP production by increasing oxygen supply. 


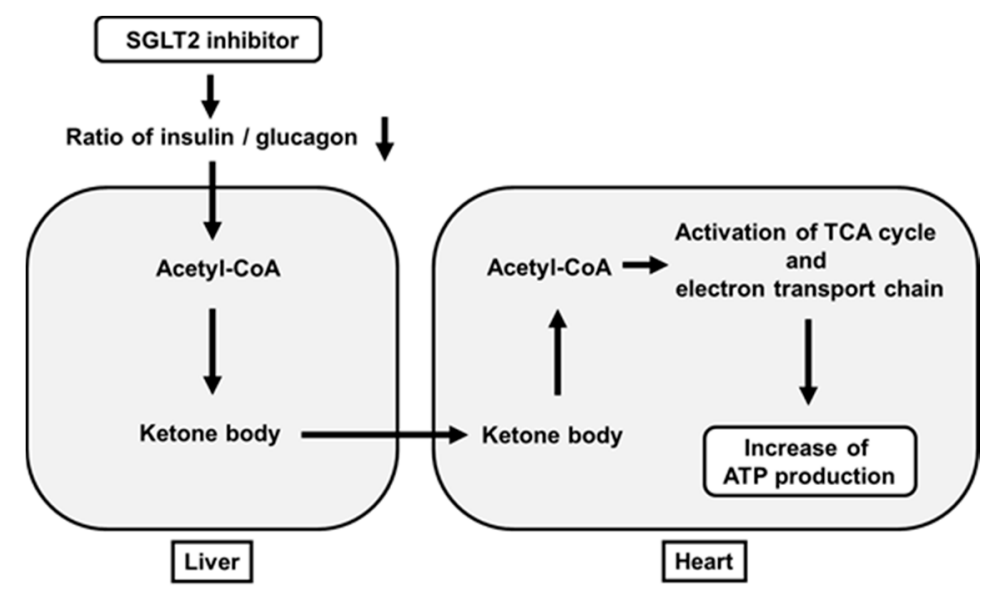

Figure 3. Favorable effects of SGLT2 inhibitors on ATP production in the heart beyond their glucoselowering effect. SGLT2 inhibitors decrease a ratio of insulin to glucagon, which leads to increased ketone bodies (acetoacetate and $\beta$-hydroxybutyrate) in the liver. Such ketone bodies are carried to the heart. After this, they activate the TCA cycle and electron transporter chain in mitochondria and finally increase ATP production in the heart.

\section{SGLT2 Inhibitors Have Substantial Renal Protective Effects}

While SGLT2 inhibitors have been used worldwide, there are various large-scale clinical trials about renal protective effects of them [63-65,69-75]. It was reported that canagliflozin had favorable effects on renal outcomes. The CANVAS program collected data from two trials with patients with T2DM and high cardiovascular risk. Patients in each trial were randomized to take canagliflozin or placebo [65]. As the results, canagliflozin treatment showed favorable effects on the progression of albuminuria (HR, 0.73). Furthermore, canagliflozin treatment showed favorable effects on the primary composite renal outcome (HR, 0.60) [65].

CREDENCE trial is another large-scale clinical study examining the effects of SGLT2 inhibitors on renal function. In this trial, patients with T2DM and albuminuric chronic kidney disease were randomized to take canagliflozin or placebo. eGFR of each patient was 30 to $<90 \mathrm{~mL} / \mathrm{min} / 1.73 \mathrm{~m}^{2}$, and all patients took renin-angiotensin system inhibitors. As a result, canagliflozin treatment reduced the primary composite renal outcome by $30 \%$ (HR, 0.70). Moreover, such treatment reduced the risk of end-stage kidney disease, doubling of serum creatinine, or renal-cause death by $34 \%$ (HR, 0.66), and reduced the risk of end-stage kidney disease by $32 \%(H R, 0.68)$ [69]. Taken together, SGLT2 inhibitor canagliflozin decreased the risk of renal failure in patients with T2DM and kidney disease for a relatively short period of time.

We also reported that effects of canagliflozin on albuminuria in patients with T2DM. The alteration of urinary albumin excretion was positively correlated with the alteration of systolic blood pressure. Furthermore, the alteration of blood pressure was an independent factor for the alteration of urinary albumin excretion in multivariate analysis; the lower the blood pressure, the better the albuminuria [76]. Taken together, canagliflozin reduces urinary albumin excretion by reducing blood pressure in patients with T2DM (Figure 4).

It has been clearly shown recently that SGLT2 inhibitors have renal protective effects. SGLT2 inhibitors improve renal outcomes by reducing urinary albumin excretion. There are various possible mechanisms for renal protective effects of SGLT2 inhibitors including the reduction of blood pressure, increase of ketone body production, increase of sirtuin-1 expression, and constriction of afferent arteriole through the tubule-glomerular feedback system (Figure 4).

First, it was reported that the single-nephron glomerular filtration rate in diabetic mice was higher compared to its control, but it was lower after treatment with empagliflozin. In vivo imaging also revealed concomitant afferent arteriolar dilation and increased glomerular permeability of albumin in diabetic mice, which was ameliorated 
after the treatment with empagliflozin [77]. Furthermore, they showed that empagliflozin increased urinary adenosine excretion, which led to reduction of hyperfiltration through afferent arteriolar constriction [77]. Second, it was reported that ketone bodies were increased by empagliflozin, which led to preservation of ATP level in the kidney. Furthermore, they showed ketone bodies reduced proteinuria in diabetic mice [78]. Third, while it was known that sirtuin-1 played important roles in various tissues as an anti-aging factor by reducing oxidative stress and inflammation, it was reported that under diabetic conditions, situin-1 expression in the kidney was decreased, which led to the progression of diabetic nephropathy $[79,80]$. It was also shown that canagliflozin increased sirtuin-1 expression in the kidney of diabetic mice and that SIRT1 expression levels were negatively correlated with SGLT2 expression levels in renal biopsy specimens from humans $[79,80]$. Taken together, SGLT2 inhibitors exert renal protective effects through a variety of pathways such as reduction of blood pressure, increase of ketone body production, increase of sirtuin-1 expression, and constriction of afferent arteriole through the tubule-glomerular feedback system (Figure 4).

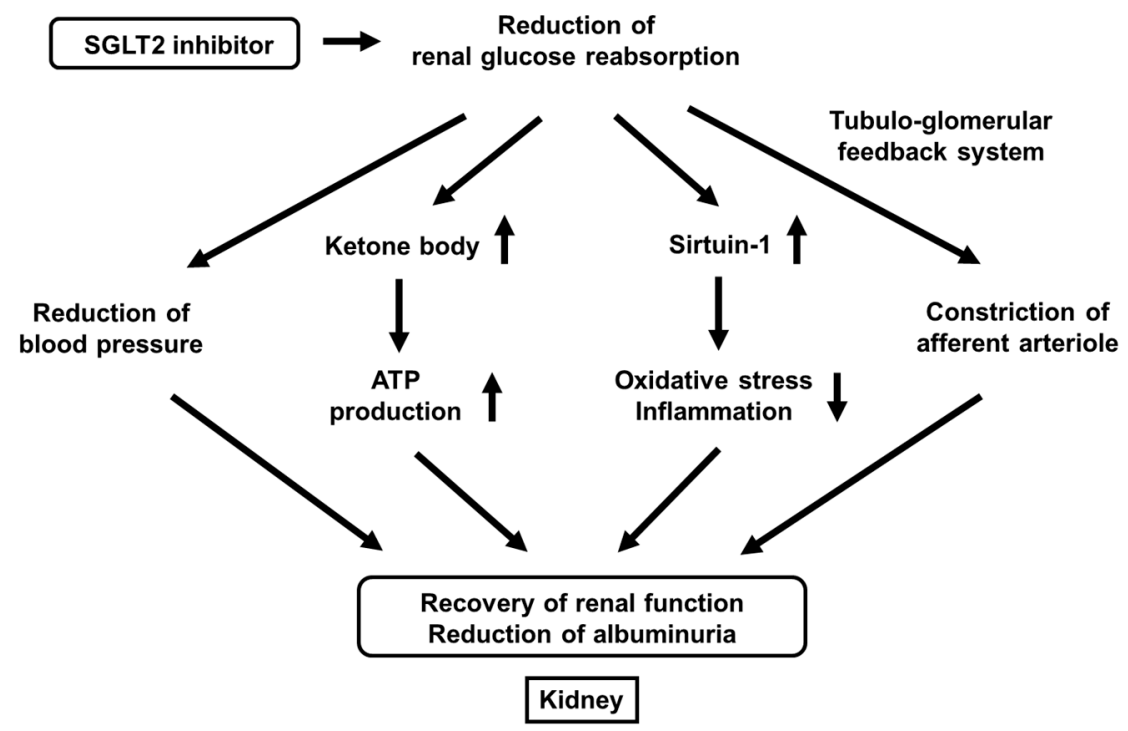

Figure 4. Favorable effects of SGLT2 inhibitors on renal function beyond their glucose-lowering effect. SGLT2 inhibitors reduce renal glucose reabsorption, which leads to the reduction of blood pressure, increase of ketone bodies, increase of sirtuin- 1 expression, and constriction of afferent arteriole. All of such alterations lead to the recovery or renal function and the reduction of albuminuria.

\section{SGLT2 Inhibitors Are Useful as an Adjuvant Therapy to Insulin Preparation in Patients with Type 1 Diabetes Mellitus}

There have been various clinical trials using SGLT2 inhibitors in patients with type 1 diabetes mellitus (T1DM). Dapagliflozin was approved as an adjuvant therapy to insulin preparation in patients with T1DM who have poor glycemic control [81,82]. In Japan, ipragliflozin as well as dapagliflozin can be used as an adjuvant therapy to insulin in patients with T1DM. As an adjuvant therapy to insulin, SGLT2 inhibitors decrease blood glucose levels with smaller dose of total daily insulin preparation. In addition, since SGLT2 inhibitors decrease body weight and insulin preparation increases body weight, starting SGLT2 inhibitor and decreasing dose of insulin preparation leads to reduction of body weight and amelioration of insulin sensitivity. When insulin dose is reduced, the risk of hypoglycemia is also decreased. Since hypoglycemia brings out various clinical problems such as acute coronary syndrome, fundus hemorrhage, and unconscious hypoglycemia due to lack of catecholamine secretion, we should avoid hypoglycemia in clinical practice. In addition, since hypoglycemia damages the brain and facilitates the development of dementia, it is very important to reduce possible hypoglycemia risk, especially in elder patients with T1DM. However, since there is some concern about diabetic ketoacidosis 
caused by SGLT2 inhibitors, we should bear in mind the possibility of diabetic ketoacidosis, especially in patients with T1DM.

\section{Side Effects of SGLT2 Inhibitors and Precautions When Using Them}

As described above, SGLT2 inhibitors have amazing multifaceted effects that are far beyond prediction. It is noted, however, that SGLT2 inhibitors have several side effects such as urinary tract infection or genital infection. Indeed, it was reported that although the effects of SGLT2 inhibitors on glycemic control were comparable to those observed in large-scale clinical trials, there were safety concerns such as the frequent occurrence of urinary tract or genital infection [83]. In addition, as described above, there is some concern about diabetic ketoacidosis caused by SGLT2 inhibitors, and thus we should bear in mind the possibility of diabetic ketoacidosis, especially in patients with T1DM. Renal sodium reabsorption and glucose metabolism are closely tied with acid-base balance, and many theories have been proposed to explain the increased risk of ketoacidosis (either hyper- or eu-glycemic) in patients on SGLT2 inhibitors. Together with genital and urinary infections (sometimes severe, limiting patient compliance or requiring hospitalization for urosepsis and pyelonephritis), the risk of ketoacidosis associated with SGLT2 inhibitors may generate confusion among treating physicians.

Recently, a new pandemic was induced by coronavirus infectious disease 2019 (COVID19) worldwide. The mortality in patients with COVID-19 is extremely high, and the main reason of death is severe pneumonia [84]. In addition, the mortality in patients with both COVID-19 and diabetes was found to be very high [85,86]. SGLT2 inhibitors may increase the likelihood of COVID-19-related ketoacidosis in patients with severe insulin deficiency in patients with T1DM or T2DM [87]. Therefore, we should always consider the benefits and the demerits of SGLT2 inhibitors.

\section{Conclusions}

SGLT2 inhibitors decrease blood glucose levels by increasing urinary glucose excretion and show amazing multifaceted effects that are far beyond prediction like some emerging magical medicine. First, SGLT2 inhibitors have some favorable effects on pancreatic $\beta$-cell function. Second, SGLT2 inhibitors mitigate insulin resistance in insulin target tissues. Third, SGLT2 inhibitors have some favorable effects on NAFLD, at least in part due to mitigation of hyperinsulinemia. Fourth, SGLT2 inhibitors have cardio-protective effects. Indeed, in several clinical trials, SGLT2 inhibitors showed some favorable effects on cardiovascular morbidity in patients with T2DM. Fifth, SGLT2 inhibitors have renal protective effects. Indeed, in several clinical trials, SGLT2 inhibitors showed some favorable effects on the progression of albuminuria in patients with T2DM. Sixth, SGLT2 inhibitors are useful as an adjuvant therapy to insulin preparation in patients with T1DM. It is noted, however, that SGLT2 inhibitors have several side effects such as urinary tract infection or genital infection. Taken together, we believe that SGLT2 inhibitors have amazing multifaceted effects beyond prediction, and thereby SGLT2 inhibitors would be very promising from the clinical point of view in a variety of aspects, although we have to be careful of their usage in several points.

Author Contributions: H.K. wrote this manuscript. A.O., T.K. (Tomohiko Kimura), M.S., T.K. (Tomoe Kinoshita), T.-a.M. and K.K. participated in the discussion. All authors have read and agreed to the published version of the manuscript.

Funding: This research received no external funding.

Institutional Review Board Statement: Not applicable.

Informed Consent Statement: Not applicable.

Conflicts of Interest: The authors declare no conflict of interest. 


\section{References}

1. Rhodes, C.J. Type 2 diabetes-a matter of beta-cell life and death? Science 2005, 307, 380-384. [CrossRef]

2. Halban, P.A.; Polonsky, K.S.; Bowden, D.W.; Hawkins, M.A.; Ling, C.; Mather, K.J.; Powers, A.C.; Rhodes, C.J.; Sussel, L.; Weir, G.C. $\beta$-Cell failure in type 2 diabetes: Postulated mechanisms and prospects for prevention and treatment. Diabetes Care 2014, 37, 1751-1758. [CrossRef]

3. Lytrivi, M.; Castell, A.L.; Poitout, V.; Cnop, M. Recent Insights Into Mechanisms of beta-Cell Lipo- and Glucolipotoxicity in Type 2 Diabetes. J. Mol. Biol. 2020, 432, 1514-1534. [CrossRef]

4. Ahn, C.H.; Oh, T.J.; Kwak, S.H.; Cho, Y.M. Sodium-glucose cotransporter-2 inhibition improves incretin sensitivity of pan-creatic beta-cells in people with type 2 diabetes. Diabetes Obes. Metab. 2018, 20, 370-377. [CrossRef] [PubMed]

5. Forst, T.; Alghdban, M.; Fischer, A.; Weber, M.; Voswinkel, S.; Heise, T.; Kapitza, C.; Plum-Mörschel, L. Sequential Treatment Escalation with Dapagliflozin and Saxagliptin Improves Beta Cell Function in Type 2 Diabetic Patients on Previous Metformin Treatment: An Exploratory Mechanistic Study. Horm. Metab. Res. 2018, 50, 403-407. [CrossRef]

6. Martinez, R.; Al-Jobori, H.; Ali, A.M.; Adams, J.; Abdul-Ghani, M.; Triplitt, C.; DeFronzo, R.A.; Cersosimo, E. Endogenous Glucose Production and Hormonal Changes in Response to Canagliflozin and Liraglutide Combination Therapy. Diabetes 2018, 67, 1182-1189. [CrossRef] [PubMed]

7. Cusi, K.; Bril, F.; Barb, D.; Polidori, D.; Sha, S.; Ghosh, A.; Bs, K.F.; Sunny, N.E.; Kalavalapalli, S.; Pettus, J.; et al. Effect of canagliflozin treatment on hepatic triglyceride content and glucose metabolism in patients with type 2 diabetes. Diabetes Obes. Metab. 2019, 21, 812-821. [CrossRef] [PubMed]

8. Scheen, A.J. Sodium-glucose cotransporter type 2 inhibitors for the treatment of type 2 diabetes mellitus. Nat. Rev. Endocrinol. 2020, 16, 556-577. [CrossRef]

9. Ali, A.M.; Mari, A.; Martinez, R.; Al-Jobori, H.; Adams, J.; Triplitt, C.; DeFronzo, R.; Cersosimo, E.; Abdul-Ghani, M. Improved Beta Cell Glucose Sensitivity Plays Predominant Role in the Decrease in HbA1c with Cana and Lira in T2DM. J. Clin. Endocrinol. Metab. 2020, 105, 3226-3233. [CrossRef]

10. Ali, A.M.; Martinez, R.; Al-Jobori, H.; Adams, J.; Triplitt, C.; DeFronzo, R.; Cersosimo, E.; Abdul-Ghani, M. Combination Therapy With Canagliflozin Plus Liraglutide Exerts Additive Effect on Weight Loss, but Not on HbA1c, in Patients With Type 2 Diabetes. Diabetes Care 2020, 43, 1234-1241. [CrossRef]

11. Lahoti, S.; Nashawi, M.; Sheikh, O.; Massop, D.; Mir, M.; Chilton, R. Sodium-glucose co-transporter 2 inhibitors and diabetic retinopathy: Insights into preservation of sight and looking beyond. Cardiovasc. Endocrinol. Metab. 2021, 10, 3-13. [CrossRef]

12. Kaneto, H.; Matsuoka, T.-A. Role of Pancreatic Transcription Factors in Maintenance of Mature $\beta$-Cell Function. Int. J. Mol. Sci. 2015, 16, 6281-6297. [CrossRef]

13. Kaneto, H.; Obata, A.; Kimura, T.; Shimoda, M.; Sanada, J.; Fushimi, Y.; Katakami, N.; Matsuoka, T.; Kaku, K. Notable Underlying Mechanism for Pancreatic $\beta$-Cell Dysfunction and Atherosclerosis: Pleiotropic Roles of Incretin and Insulin Signaling. Int. J. Mol. Sci. 2020, 21, 9444. [CrossRef] [PubMed]

14. Matsuoka, T.-A.; Kaneto, H.; Miyatsuka, T.; Yamamoto, T.; Yamamoto, K.; Kato, K.; Shimomura, I.; Stein, R.; Matsuhisa, M. Regulation of MafA Expression in Pancreatic -Cells in db/db Mice With Diabetes. Diabetes 2010, 59, 1709-1720. [CrossRef] [PubMed]

15. Matsuoka, T.-A.; Kaneto, H.; Kawashima, S.; Miyatsuka, T.; Tochino, Y.; Yoshikawa, A.; Imagawa, A.; Miyazaki, J.-I.; Gannon, M.; Stein, R.; et al. Preserving Mafa Expression in Diabetic Islet $\beta$-Cells Improves Glycemic Control in Vivo. J. Biol. Chem. 2015, 290, 7647-7657. [CrossRef] [PubMed]

16. Yamamoto, Y.; Miyatsuka, T.; Sasaki, S.; Miyashita, K.; Kubo, N.; Shimo, N.; Takebe, S.; Watada, H.; Kaneto, H.; Matsuoka, T.; et al. Recovered expression of Pdx1 improves $\beta$-cell failure in diabetic mice. Biochem. Biophys. Res. Commun. 2017, 483, $418-424$. [CrossRef]

17. Shimoda, M.; Kanda, Y.; Hamamoto, S.; Tawaramoto, K.; Hashiramoto, M.; Matsuki, M.; Kaku, K. The human glucagon-like peptide-1 analogue liraglutide preserves pancreatic beta cells via regulation of cell kinetics and suppression of oxidative and endoplasmic reticulum stress in a mouse model of diabetes. Diabetologia 2011, 54, 1098-1108. [CrossRef]

18. Kimura, T.; Kaneto, H.; Shimoda, M.; Hirukawa, H.; Okauchi, S.; Kohara, K.; Hamamoto, S.; Tawaramoto, K.; Hashiramoto, M.; $\mathrm{Kaku}, \mathrm{K}$. Protective effects of pioglitazone and/or liraglutide on pancreatic $\beta$-cells in $\mathrm{db} / \mathrm{db}$ mice: Comparison of their effects between in an early and advanced stage of diabetes. Mol. Cell. Endocrinol. 2015, 400, 78-89. [CrossRef] [PubMed]

19. Hirukawa, H.; Kaneto, H.; Shimoda, M.; Kimura, T.; Okauchi, S.; Obata, A.; Kohara, K.; Hamamoto, S.; Tawaramoto, K.; Hashiramoto, M.; et al. Combination of DPP-4 inhibitor and PPAR $\gamma$ agonist exerts protective effects on pancreatic $\beta$-cells in diabetic $\mathrm{db} / \mathrm{db}$ mice through the augmentation of IRS-2 expression. Mol. Cell. Endocrinol. 2015, 413, 49-60. [CrossRef]

20. Hamamoto, S.; Kanda, Y.; Shimoda, M.; Tatsumi, F.; Kohara, K.; Tawaramoto, K.; Hashiramoto, M.; Kaku, K. Vildagliptin preserves the mass and functionof pancreatic beta cells via the developmental regulation and suppression of oxidative stress and endoplasmic reticulum stress in a mouse model of diabetes. Diabetes Obes. Metab. 2013, 15, 153-163. [CrossRef]

21. Kusakabe, T.; Yokota, S.; Shimizu, M.; Inoue, T.; Tanaka, M.; Ohue-Kitano, R.; Muranaka, K.; Yamakage, H.; Wada, H.; Hasegawa, K.; et al. Differential effects of sodium-glucose cotransporter 2 inhibitor and low-carbohydrate diet on body composition and metabolic profile in obese diabetic db/db mice. BMJ Open Diabetes Res. Care 2020, 8, e001303. [CrossRef]

22. Hogan, M.F.; Hackney, D.J.; Aplin, A.C.; O Mundinger, T.; Larmore, M.J.; Castillo, J.J.; Esser, N.; Zraika, S.; Hull, R.L. SGLT2-i improves markers of islet endothelial cell function in $\mathrm{db} / \mathrm{db}$ diabetic mice. J. Endocrinol. 2021, 248, 95-106. [CrossRef] [PubMed] 
23. Mukai, Y.; Rikitake, Y.; Shiojima, I.; Wolfrum, S.; Satoh, M.; Takeshita, K.; Hiroi, Y.; Salomone, S.; Kim, H.H.; Benjamin, L.E.; et al. Decreased vascular lesion formation in mice with inducible endothelial-specific expression of protein ki-nase Akt. J. Clin. Investig. 2006, 116, 334-343. [CrossRef]

24. Kubota, T.; Kubota, N.; Kumagai, H.; Yamaguchi, S.; Kozono, H.; Takahashi, T.; Inoue, M.; Itoh, S.; Takamoto, I.; Sasako, T.; et al. Impaired Insulin Signaling in Endothelial Cells Reduces Insulin-Induced Glucose Uptake by Skeletal Muscle. Cell Metab. 2011, 13, 294-307. [CrossRef]

25. Hashimoto, S.; Kubota, N.; Sato, H.; Sasaki, M.; Takamoto, I.; Kubota, T.; Nakaya, K.; Noda, M.; Ueki, K.; Kadowaki, T. Insu-lin receptor substrate-2 (Irs2) in endothelial cells plays a crucial role in insulin secretion. Diabetes 2015, 64, 876-886. [CrossRef] [PubMed]

26. Obata, A.; Kimura, T.; Obata, Y.; Shimoda, M.; Kinoshita, T.; Kohara, K.; Okauchi, S.; Hirukawa, H.; Kamei, S.; Nakanishi, S.; et al. Vascular endothelial PDK1 plays pivotal roles for maintenance of pancreatic beta-cell mass and function in adult male mice. Diabetologia 2019, 62, 1225-1236. [CrossRef]

27. Suzuki, M.; Honda, K.; Fukazawa, M.; Ozawa, K.; Hagita, H.; Kawai, T.; Takeda, M.; Yata, T.; Kawai, M.; Fukuzawa, T.; et al. Tofogliflozin, a potent and highly specific sodium/glucose cotransporter 2 inhib-itor, improves glycemic control in diabetic rats and mice. J. Pharmacol. Exp. Ther. 2012, 341, 692-701. [CrossRef] [PubMed]

28. Lapuerta, P.; Zambrowicz, B.; Strumph, P.; Sands, A. Development of sotagliflozin, a dual sodium-dependent glucose trans-porter 1/2 inhibitor. Diab. Vasc. Dis. Res. 2015, 12, 101-110. [CrossRef]

29. Abdul-Ghani, M.; Al Jobori, H.; Daniele, G.; Adams, J.; Cersosimo, E.; Triplitt, C.; DeFronzo, R.A. Inhibition of renal sodi-umglucose cotransport with empagliflozin lowers fasting plasma glucose and improves beta-cell function in subjects with impaired fasting glucose. Diabetes 2017, 66, 2495-2502. [CrossRef]

30. Al Jobori, H.; Daniele, G.; Adams, J.; Cersosimo, E.; Solis-Herrera, C.; Triplitt, C.; DeFronzo, R.A.; Abdul-Ghani, M. Empagli-flozin treatment is associated with improved beta-cell function in type 2 diabetes mellitus. J. Clin. Endocrinol. Metab. 2018, 103, 1402-1407. [CrossRef]

31. Shirakawa, J.; Tajima, K.; Okuyama, T.; Kyohara, M.; Togashi, Y.; De Jesus, D.F.; Basile, G.; Kin, T.; Shapiro, A.M.J.; Kulkarni, R.N.; et al. Luseogliflozin increases beta cell proliferation through humoral factors that activate an insulin receptor- and IGF-1 receptor-independent pathway. Diabetologia 2020, 63, 577-587. [CrossRef] [PubMed]

32. Wei, R.; Cui, X.; Feng, J.; Gu, L.; Lang, S.; Wei, T.; Yang, J.; Liu, J.; Le, Y.; Wang, H.; et al. Dapagliflozin promotes beta cell regeneration by inducing pancreatic endocrine cell phenotype conversion in type 2 diabetic mice. Metabolism 2020, 111, 154324. [CrossRef] [PubMed]

33. Saisho, Y. An emerging new concept for the management of type 2 diabetes with a paradigm shift from the glucose-centric to beta cell-centric concept of diabetes-An Asian perspective. Expert Opin. Pharmacother. 2020, 1-13. [CrossRef] [PubMed]

34. Shimo, N.; Matsuoka, T.; Miyatsuka, T.; Takebe, S.; Tochino, Y.; Takahara, M.; Kaneto, H.; Shimomura, I. Short-term selec-tive alleviation of glucotoxicity and lipotoxicity ameliorates the suppressed expression of key $\beta$-cell factors under diabetic conditions. Biochem. Biophys. Res. Commun. 2015, 467, 948-954. [CrossRef] [PubMed]

35. Okauchi, S.; Shimoda, M.; Obata, A.; Kimura, T.; Hirukawa, H.; Kohara, K.; Mune, T.; Kaku, K.; Kaneto, H. Protective ef-fects of SGLT2 inhibitor luseogliflozin on pancreatic $\beta$-cells in obese type 2 diabetic $\mathrm{db} / \mathrm{db}$ mice. Biochem. Biophys. Res. Commun. 2016, 470, 772-782. [CrossRef] [PubMed]

36. Kimura, T.; Obata, A.; Shimoda, M.; Okauchi, S.; Kanda-Kimura, Y.; Nogami, Y.; Hirukawa, H.; Kohara, K.; Nakanishi, S.; Mune, T.; et al. Protective effects of SGLT2 inhibitor luseogliflozin on pancreatic $\beta$-cells in obese diabetic $\mathrm{db} / \mathrm{db}$ mice: The earlier and longer, the better. Diabetes Obes. Metab. 2018, 20, 2442-2457. [CrossRef]

37. Stanojevic, V.; Habener, J.F. Evolving function and potential of pancreatic alpha cells. Best Pr. Res. Clin. Endocrinol. Metab. 2015, 29, 859-871. [CrossRef] [PubMed]

38. Bonner, C.C.; Kerr-Conte, J.J.; Gmyr, V.V.; Queniat, G.G.; Moerman, E.E.; Thévenet, J.J.; Beaucamps, C.C.; Delalleau, N.N.; Popescu, I.I.; Malaisse, W.J.; et al. Inhibition of the glucose transporter SGLT2 with dapagliflozin in pancreatic alpha cells triggers glucagon secretion. Nat. Med. 2015, 21, 512-517. [CrossRef]

39. Solini, A.; Sebastiani, G.; Nigi, L.; Santini, E.; Rossi, C.; Dotta, F. Dapagliflozin modulates glucagon secretion in an SGLT2independent manner in murine alpha cells. Diabetes Metab. 2017, 43, 512-520. [CrossRef]

40. Kuhre, R.E.; Ghiasi, S.M.; Adriaenssens, A.E.; Albrechtsen, N.J.W.; Andersen, D.B.; Aivazidis, A.; Chen, L.; Mandrup-Poulsen, T.; Ørskov, C.; Gribble, F.M.; et al. No direct effect of SGLT2 activity on glucagon secretion. Diabetologia 2019, 62, 1011-1023. [CrossRef]

41. Yokono, M.; Takasu, T.; Hayashizaki, Y.; Mitsuoka, K.; Kihara, R.; Muramatsu, Y.; Miyoshi, S.; Tahara, A.; Kurosaki, E.; Li, Q.; et al. SGLT2 selective inhibitor ipragliflozin reduces body fat mass by increasing fatty acid oxidation in high-fat diet-induced obese rats. Eur. J. Pharmacol. 2014, 727, 66-74. [CrossRef] [PubMed]

42. Suzuki, M.; Takeda, M.; Kito, A.; Fukazawa, M.; Yata, T.; Yamamoto, M.; Nagata, T.; Fukuzawa, T.; Yamane, M.; Honda, K.; et al. Tofogliflozin, a sodium/glucose cotransporter 2 inhibitor, attenuates body weight gain and fat accumulation in diabetic and obese animal models. Nutr. Diabetes 2014, 4, e125. [CrossRef]

43. Cefalu, W.T. Paradoxical insights into whole body metabolic adaptations following SGLT2 inhibition. J. Clin. Investig. 2014, 124, 485-487. [CrossRef] 
44. Ferrannini, E.; Muscelli, E.; Frascerra, S.; Baldi, S.; Mari, A.; Heise, T.; Broedl, U.C.; Woerle, H.J. Metabolic response to sodiumglucose cotransporter 2 inhibition in type 2 diabetic patients. J. Clin. Investig. 2014, 124, 499-508. [CrossRef]

45. Merovci, A.; Solis-Herrera, C.; Daniele, G.; Eldor, R.; Fiorentino, T.V.; Tripathy, D.; Xiong, J.; Perez, Z.; Norton, L.; Abdul-Ghani, M.A.; et al. Dapagliflozin improves muscle insulin sensitivity but enhances endogenous glucose production. J. Clin. Investig. 2014, 124, 509-514. [CrossRef] [PubMed]

46. Obata, A.; Kubota, N.; Kubota, T.; Iwamoto, M.; Sato, H.; Sakurai, Y.; Takamoto, I.; Katsuyama, H.; Suzuki, Y.; Fukazawa, M.; et al. Tofogliflozin Improves Insulin Resistance in Skeletal Muscle and Accelerates Lipolysis in Adipose Tissue in Male Mice. Endocrinology 2016, 157, 1029-1042. [CrossRef]

47. Kamei, S.; Iwamoto, M.; Kameyama, M.; Shimoda, M.; Kinoshita, T.; Obata, A.; Kimura, T.; Hirukawa, H.; Tatsumi, F.; Kohara, K.; et al. Effect of Tofogliflozin on Body Composition and Glycemic Control in Japanese Subjects with Type 2 Diabetes Mellitus. J. Diabetes Res. 2018, 2018, 1-6. [CrossRef] [PubMed]

48. Ballestri, S.; Zona, S.; Targher, G.; Romagnoli, D.; Baldelli, E.; Nascimbeni, F.; Roverato, A.; Guaraldi, G.; Lonardo, A. Non-alcoholic fatty liver disease is associated with an almost twofold increased risk of incident type 2 diabetes and metabolic syn-drome. Evidence from a systematic review and meta-analysis. J. Gastroenterol. Hepatol. 2016, 31, 936-944. [CrossRef]

49. Italian Association for the Study of the Liver (AISF). AISF position paper on nonalcoholic fatty liver disease (NAFLD): Up-dates and future directions. Dig Liver Dis. 2017, 49, 471-483. [CrossRef] [PubMed]

50. Ballestri, S.; Nascimbeni, F.; Romagnoli, D.; Baldelli, E.; Lonardo, A. The Role of Nuclear Receptors in the Pathophysiology, Natural Course, and Drug Treatment of NAFLD in Humans. Adv. Ther. 2016, 33, 291-319. [CrossRef]

51. Rinella, M.E. Nonalcoholic fatty liver disease: A systematic review. JAMA 2015, 313, 2263-2273. [CrossRef]

52. Bril, F.; Cusi, K. Management of Nonalcoholic Fatty Liver Disease in Patients with Type 2 Diabetes: A Call to Action. Diabetes Care 2017, 40, 419-430. [CrossRef]

53. Mungamuri, S.K.; Sinha, S.N.; Javvadi, Y. Understanding the Alterations in Lipid Metabolism in NAFLD Progression: Current Trends and Future Directions. Crit. Rev. Oncog. 2021, 26, 35-49. [CrossRef] [PubMed]

54. Han, M.A.T.; Yu, Q.; Tafesh, Z.; Pyrsopoulos, N. Diversity in NAFLD: A Review of Manifestations of Nonalcoholic Fatty Liver Disease in Different Ethnicities Globally. J. Clin. Transl. Hepatol. 2020, 1-10. [CrossRef] [PubMed]

55. Cusi, K. Treatment of patients with type 2 diabetes and non-alcoholic fatty liver disease: Current approaches and future di-rections. Diabetologia 2016, 59, 1112-1120. [CrossRef]

56. Portillo-Sanchez, P.; Cusi, K. Treatment of Nonalcoholic Fatty Liver Disease (NAFLD) in patients with Type 2 Diabetes Mellitus. Clin. Diabetes Endocrinol. 2016, 2, 9. [CrossRef]

57. Sumida, Y.; Seko, Y.; Yoneda, M.; Japan Study Group of NAFLD (JSG-NAFLD). Novel antidiabetic medications for non-alcoholic fatty liver disease with type 2 diabetes mellitus. Hepatol. Res. 2017, 47, 266-280. [CrossRef] [PubMed]

58. Ito, D.; Shimizu, S.; Inoue, K.; Saito, D.; Yanagisawa, M.; Inukai, K.; Akiyama, Y.; Morimoto, Y.; Noda, M.; Shimada, A. Comparison of Ipragliflozin and Pioglitazone Effects on Nonalcoholic Fatty Liver Disease in Patients With Type 2 Diabetes: A Randomized, 24-Week, Open-Label, Active-Controlled Trial. Diabetes Care 2017, 40, 1364-1372. [CrossRef]

59. Kinoshita, T.; Shimoda, M.; Sanada, J.; Fushimi, Y.; Nishioka, M.; Hirata, Y.; Irie, S.; Obata, A.; Kimura, T.; Hirukawa, H.; et al. There is a close association between the re-covery of liver injury and glycemic control after SGLT2 inhibitor treatment in Japanese subjects with type 2 diabetes: A retro-spective clinical study. Diabetes Ther. 2018, 9, 1569-1580. [CrossRef]

60. Kinoshita, T.; Shimoda, M.; Nakashima, K.; Fushimi, Y.; Hirata, Y.; Tanabe, A.; Tatsumi, F.; Hirukawa, H.; Sanada, J.; Ko-hara, K.; et al. Comparison of effects of three kinds of glucose-lowering drugs on nonalcoholic fatty liver disease in cases with type 2 diabetes: A ran-domized, open-label, 3-arm active-control study. J. Diabetes Investig. 2020, 11, 1612-1622. [CrossRef]

61. Wong, C.; Yaow, C.Y.L.; Ng, C.H.; Chin, Y.H.; Low, Y.F.; Lim, A.Y.L.; Muthiah, M.D.; Khoo, C.M. Sodium-Glucose Co-Transporter 2 Inhibitors for Non-Alcoholic Fatty Liver Disease in Asian Patients With Type 2 Diabetes: A Meta-Analysis. Front. Endocrinol. 2021, 11, 609135. [CrossRef] [PubMed]

62. Zinman, B.; Wanner, C.; Lachin, J.M.; Fitchett, D.; Bluhmki, E.; Hantel, S.; Mattheus, M.; Devins, T.; Johansen, O.E.; Woerle, H.J.; et al. Empagliflozin, cardiovascular outcomes, and mor-tality in type 2 diabetes. N. Engl. J. Med. 2015, 373, 2117-2128. [CrossRef]

63. Heerspink, H.J.; Perkins, B.A.; Fitchett, D.H.; Husain, M.; Cherney, D.Z. Sodium glucose cotransporter 2 inhibitors in the treatment of diabetes mellitus: Cardiovascular and kidney effects, potential mechanisms, and clinical applications. Circulation 2016, 134, 752-772. [CrossRef] [PubMed]

64. Ferrannini, E.; Mark, M.; Mayoux, E. CV Protection in the EMPA-REG OUTCOME Trial: A “Thrifty Substrate” Hypothesis. Diabetes Care 2016, 39, 1108-1114. [CrossRef]

65. Neal, B.; Perkovic, V.; Mahaffey, K.W.; De Zeeuw, D.; Fulcher, G.; Erondu, N.; Shaw, W.; Law, G.; Desai, M.; Matthews, D.R. Canagliflozin and Cardiovascular and Renal Events in Type 2 Diabetes. N. Engl. J. Med. 2017, 377, 644-657. [CrossRef] [PubMed]

66. Kaku, K.; Lee, J.; Mattheus, M.; Kaspers, S.; George, J.; Woerle, H.J.; EMPA-REG OUTCOME Investigators. Empagliflozin and cardiovascular outcomes in Asian patients with type 2 diabetes and established cardiovascular disease-Results from EM-PA-REG OUTCOME. Circ. J. 2017, 81, 227-234. [CrossRef]

67. Zannad, F.; Ferreira, J.P.; Pocock, S.J.; Anker, S.D.; Butler, J.; Filippatos, G.; Brueckmann, M.; Ofstad, A.P.; Pfarr, E.; Jamal, W.; et al. SGLT2 inhibitors in patients with heart failure with reduced ejection fraction: A meta-analysis of the EMPER-OR-Reduced and DAPA-HF trials. Lancet 2020, 396, 819-829. [CrossRef] 
68. Kashiwagi, A.; Araki, S.; Maegawa, H. Sodium-glucose cotransporter 2 inhibitors represent a paradigm shift in the preven-tion of heart failure in type 2 diabetes patients. J. Diabetes Investig. 2021, 12, 6-20. [CrossRef] [PubMed]

69. Perkovic, V.; Jardine, M.J.; Neal, B.; Bompoint, S.; Heerspink, H.J.; Charytan, D.M.; Edwards, R.; Agarwal, R.; Bakris, G.; Bull, S.; et al. Canagliflozin and Renal Outcomes in Type 2 Diabetes and Nephropathy. N. Engl. J. Med. 2019, 380, 2295-2306. [CrossRef] [PubMed]

70. Cherney, D.Z.; Odutayo, A.; Verma, S. A Big Win for Diabetic Kidney Disease: CREDENCE. Cell Metab. 2019, 29, 1024-1027. [CrossRef]

71. Neuen, B.L.; Young, T.; Heerspink, H.J.L.; Neal, B.; Perkovic, V.; Billot, L.; Mahaffey, K.W.; Charytan, D.M.; Wheeler, D.C.; Arnott, C.; et al. SGLT2 inhibitors for the prevention of kidney failure in patients with type 2 diabetes: A systematic review and meta-analysis. Lancet Diabetes Endocrinol. 2019, 7, 845-854. [CrossRef]

72. Nangaku, M. Light of dawn in Melbourne: SONAR and CREDENCE. Kidney Int. 2019, 96, 2-4. [CrossRef] [PubMed]

73. Oshima, M.; Neuen, B.L.; Jardine, M.J.; Bakris, G.; Edwards, R.; Levin, A.; Mahaffey, K.W.; Neal, B.; Pollock, C.; Rosenthal, N.; et al. Effects of canagliflozin on anaemia in patients with type 2 dia-betes and chronic kidney disease: A post-hoc analysis from the CREDENCE trial. Lancet Diabetes Endocrinol. 2020, 8, 903-914. [CrossRef]

74. Giugliano, D.; De Nicola, L.; Maiorino, M.I.; Bellastella, G.; Garofalo, C.; Chiodini, P.; Ceriello, A.; Esposito, K. Preventing major adverse cardiovascular events by SGLT-2 inhibition in patients with type 2 diabetes: The role of kidney. Cardiovasc. Diabetol. 2020, 19, 1-6. [CrossRef] [PubMed]

75. Kitada, M.; Hirai, T.; Koya, D. Significance of SGLT2 inhibitors: Lessons from renal clinical outcomes in patients with type 2 diabetes and basic researches. Diabetol. Int. 2020, 11, 245-251. [CrossRef] [PubMed]

76. Fushimi, Y.; Obata, A.; Sanada, J.; Iwamoto, Y.; Mashiko, A.; Horiya, M.; Mizoguchi-Tomita, A.; Nishioka, M.; Kan, Y.; Kinoshita, T.; et al. Effect of Combination Therapy of Canagliflozin Added to Teneligliptin Monotherapy in Japanese Subjects with Type 2 Diabetes Mellitus: A Retrospective Study. J. Diabetes Res. 2020, 2020, 4861681. [CrossRef] [PubMed]

77. Kidokoro, K.; Cherney, D.Z.I.; Bozovic, A.; Nagasu, H.; Satoh, M.; Kanda, E.; Sasaki, T.; Kashihara, N. Evaluation of glo-merular hemodynamic function by empagliflozin in diabetic mice using in vivo imaging. Circulation 2019, 140, 303-315. [CrossRef] [PubMed]

78. Tomita, I.; Kume, S.; Sugahara, S.; Osawa, N.; Yamahara, K.; Yasuda-Yamahara, M.; Takeda, N.; Chin-Kanasaki, M.; Kaneko, T.; Mayoux, E.; et al. SGLT2 Inhibition Mediates Protection from Diabetic Kidney Disease by Promoting Ketone Body-Induced mTORC1 Inhibition. Cell Metab. 2020, 32, 404-419.e6. [CrossRef]

79. Umino, H.; Hasegawa, K.; Minakuchi, H.; Muraoka, H.; Kawaguchi, T.; Kanda, T.; Tokuyama, H.; Wakino, S.; Itoh, H. High Basolateral Glucose Increases Sodium-Glucose Cotransporter 2 and Reduces Sirtuin-1 in Renal Tubules through Glucose Transporter-2 Detection. Sci. Rep. 2018, 8, 1-13. [CrossRef]

80. Parker, M. Interplay of adenosine monophosphate-activated protein kinase/sirtuin-1 activation and sodium influx inhibition mediates the renal benefits of sodium-glucose co-transporter-2 inhibitors in type 2 diabetes: A novel conceptual framework Diabetes Obes. Metab. 2020, 22, 734-742.

81. Li, N.; Chen, R.; Liu, K. Sodium-Glucose Cotransporter Inhibitors for the Treatment of Type 1 Diabetes Mellitus. Clin. Drug Investig. 2020, 40, 991-1000. [CrossRef]

82. Huang, Y.; Jiang, Z.; Wei, Y. Short and Medium-Term Efficacy of Sodium Glucose Cotransporter-2 (SGLT-2) Inhibitors for the Treatment of Type 1 Diabetes: Systematic Review and Meta-Analysis. Endokrynol. Polska 2020, 71, 325-333. [CrossRef] [PubMed]

83. Mirabelli, M.; Chiefari, E.; Caroleo, P.; Vero, R.; Brunetti, F.S.; Corigliano, D.M.; Arcidiacono, B.; Foti, D.P.; Puccio, L.; Brunetti, A. Long-Term Effectiveness and Safety of SGLT-2 Inhibitors in an Italian Cohort of Patients with Type 2 Diabetes Mellitus. J. Diabetes Res. 2019, 2019, 1-8. [CrossRef] [PubMed]

84. Zhu, N.; Zhang, D.; Wang, W.; Li, X.; Yang, B.; Song, J.; Zhao, X.; Huang, B.; Shi, W.; Lu, R.; et al. China Novel Coronavirus Investigating and Research Team. A novel coronavirus from patients with pneumonia in China, 2019. N. Engl. J. Med. 2020, 382, 727-733. [CrossRef]

85. Guan, W.J.; Ni, Z.Y.; Hu, Y.; Liang, W.H.; Ou, C.Q.; He, J.X.; Liu, L.; Shan, H.; Lei, C.L.; Hui, D.S.C.; et al. Clinical Characteristics of Coronavirus Disease 2019 in China. N. Engl. J. Med. 2020, 382, 1708-1720. [CrossRef]

86. Huang, I.; Lim, M.A.; Pranata, R. Diabetes mellitus is associated with increased mortality and severity of disease in COVID-19 pneumonia-A systematic review, meta-analysis, and meta-regression. Diabetes Metab. Syndr. Clin. Res. Rev. 2020, 14, 395-403. [CrossRef] [PubMed]

87. Mirabelli, M.; Chiefari, E.; Puccio, L.; Foti, D.P.; Brunetti, A. Potential Benefits and Harms of Novel Antidiabetic Drugs During COVID-19 Crisis. Int. J. Environ. Res. Public Health 2020, 17, 3664. [CrossRef] [PubMed] 